\title{
Application of an improved system of electrophoresis in acrylamide gel to studies on the sera of different species
}

\author{
N. ST. G. HYSLOP \\ From the Animal Pathology Division, Health of Animals Branch, Canada Department of Agriculture, \\ Animal Diseases Research Institute, Hull, Quebec, Canada
}

SYNOPSIS Polyacrylamide gels constitute a generally better matrix for routine electrophoresis of serum proteins than other media commonly employed, but the immunoglobulin fractions of the largest size may not migrate into gels in which the acrylamide concentration exceeds $5 \%$. To facilitate adequate separation, slabs containing a semi-solid layer were prepared from discontinuous gels consisting of 2 to $8 \%$ acrylamide. Serum samples were subjected to electrophoresis, under carefully

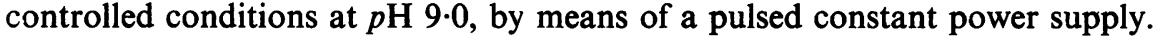

The method provided a rapid, reproducible, and relatively simple technique for the study of human serum proteins, either by electrophoresis or by immunoelectrophoresis, and for differentiation of serum samples from various animal species.

Electrophoresis in polyacrylamide gels (Raymond and Weintraub, 1959) results in a separation of protein fractions which is usually superior to the separation achieved by other means. Older methods usually depend principally on 'pore-limit' (ie size) electrophoresis (Slater, 1965) and several employed discontinuous gels to achieve improved resolution (Ornstein, 1964; Davis, 1964). Further sharpening may be achieved by discontinuities in buffer ions and in $p \mathbf{H}$. During isotachophoresis, when the sample is arranged initially between leading and trailing ions in a matrix having pores larger than the sample components, concentration and re-arranging effects result from rapid changes in conductivity during passage of the ionic boundary, thus sharpening the separation of protein bands which are migrating in the matrix. This 'Kolrausch phenomenon' may also cause a marked change in $p \mathrm{H}$ with boundary passage.

In the earliest methods gels were cast in glass cylinders, but casting in rectangular slabs permits comparison of several samples in the same matrix (Raymond, 1962; Allen and Moore, 1966; Allen, Moore, and Dilworth, 1969; Dewar and Latner, 1970). Because of difficulties in extruding gels from cylinders and in their subsequent manipulation, the majority of systems have employed relatively 'stiff' gels. The pore sizes produced in such gels, ie those containing more than $5 \%$ acrylamide, tend to hold Received for publication 14 December 1971. back the larger protein molecules to an extent at which the separation of gammaglobulins is unsatisfactory; when a gel consisting of $6 \%$ acrylamide is used the IgM fraction may not migrate away from the origin (Felgenhauer, 1970). Small-pore gels are desirable for adequate separation of the smaller molecules in the albumin and alpha-globulin regions, but acylamide concentrations as low as $4 \%$ have been employed to produce large-pore gels for segregating the gammaglobulins.

This report records the use of multilayered gels ( $2 \%-8 \%$ acrylamide) for the separation of serum proteins: the layer of the gel gradient to which the sample is applied is semi-solid, and may be discarded before fixing and staining the albumin and globulin zones. However, some proteins of molecular weight greater than that of the immunuglobulins may be retained in the $2 \%$ layer.

\section{Materials and Methods}

Polymerizing and cross-linking solutions were prepared in tris-sulphate buffer $\left(p \mathrm{H} 9.0\right.$ at $\left.25^{\circ} \mathrm{C}\right)$ from acrylamide and methylene bis-acrylamide crystals, which had been recrystallized twice from chloroform or acetone respectively (analytical grade), with $\mathbf{N}, \mathbf{N}, \mathbf{N}^{1}, \mathbf{N}^{1}$-tetramethylethylenediamine and ammonium persulphate catalyst. Gels were cast in hard glass cells ${ }^{1}$ of slightly trapezoidal section as ${ }^{1}$ Ortec Inc, 110 Midland Road, Oak Ridge, Tennessee, USA. 
shown in Table 1, each zone being water-layered during polymerization at $26^{\circ} \mathrm{C}$ in a thermostatically controlled cabinet. A light Teflon well-forming template was suspended in contact with the semisolid $2 \%$ layer and the $8 \%$ specimen-holding gel was poured around it. Considerable care was necessary in withdrawing the template to avoid rupture of the gels. After applying 20 Lambda of a serum-sucrose mixture $(250 \mu \mathrm{g}$ of protein) the wells were capped with $8 \%$ gel. The matrix system finally adopted is shown in Table $\mathrm{I}$.

\begin{tabular}{llll}
\hline Component & $\begin{array}{c}\text { Depth } \\
(\mathrm{mm})\end{array}$ & $\begin{array}{c}\text { Acrylamide } \\
\text { Concentration } \\
(\%)\end{array}$ & Molarity \\
\hline Sealing gel & - & 8 & 0.075 \\
Well-forming gel and sample & 12 & 8 & 0.075 \\
Semi-solid gel & 4 & 2 & 0.375 \\
Soft gel & 5 & $4 \frac{1}{2}$ & $0 \cdot 375$ \\
Solid gel & 9 & $6 \frac{1}{2}$ & $0 \cdot 375$ \\
Solid gel & 16 & 7 & 0.375 \\
Solid gel & 40 & 8 & 0.375 \\
Upper and lower buffers tris borate $0.065 \mathrm{M}$ & \\
Starting $p \mathrm{H} 9.0$ & & & \\
\hline
\end{tabular}

Table I Characteristics of discontinuous polyacrylamide gel slab before electrophoresis

Electrophoresis of paired slabs was allowed to continue for one hour 45 minutes at $4{ }^{\circ} \mathrm{C}$ in an Ortec $^{1}$ tank containing $0.065 \mathrm{M}$ tris borate upper and

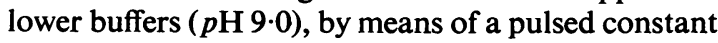
power supply ${ }^{1}(400$ volts at 300 pulses per second, mean output 37.38 watts). The upper buffer contained a tracking dye, faint traces of which may remain in the gel slabs.

For visual or densitometric examination, slabs were fixed in $12 \%$ trichloroacetic acid, then stained for 12 hours in Coomassie Brilliant Blue and decolourized in distilled water.

\section{Results}

Excellent resolution was evident throughout the gamma-globulin region, as well as in the albumin, alpha-, and beta-globulin regions. Figure 1 shows the efficacy of this technique in comparison with a system employing a $6 \%$ acrylamide slab, run concurrently under identical conditions; the technique was also markedly superior to a similar system employing a gradient of $4 \frac{1}{2}, 6$, and $8 \%$ acrylamide and the same buffers.

The ability of the quintuple gel method to detect manifest disparity in the relative mobilities of the corresponding protein fractions in sera from various animal species, as illustrated by Fig. 2, is being applied to current studies on the determination of ${ }^{1}$ Ortec Inc, 1400 Midland Road, Oak Ridge, Tennessee, USA.

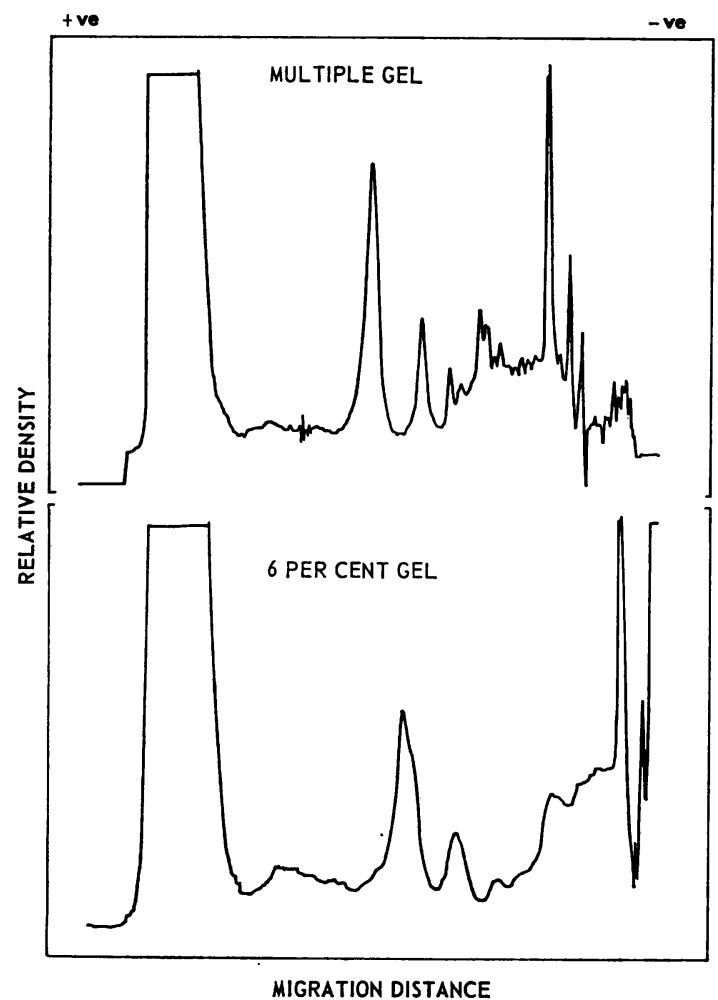

Fig. 1 Comparison of electrophoretic resolution of serum proteins in $6 \%$ acrylamide gel and in multiple gradient gel.

species differences. Figure 3 illustrates the reproducibility of results obtained with 10 bovine sera; individual differences in protein concentration caused some variation in the intensity of staining, but the migration rates of each of the major protein bands remained similar in all samples.

The hard glass cells were used to cast gel slabs prepared by four techniques representative of existing methods: method 1 is as described above; method 2, a photopolymerized 'disc' gel (Davis, 1964); method 3 , a chemically polymerized $6 \%$ gel (Felgenhauer, 1970); and method 4, a chemically polymerized continuous gradient gel (Margolis and Kenrick, 1967). Ionic and electrical conditions were established to conform as nearly as possible with the original descriptions. In all experiments electrophoresis of serum samples was continued until the albumin had migrated to the same mark on the cell. The slopes of the leading and trailing edges of the major transferrin fraction (measured from 10 to $80 \%$ peak amplitude) were estimated from the densitometer recordings of replicate serum samples from different animals. Results, shown in Table II, 


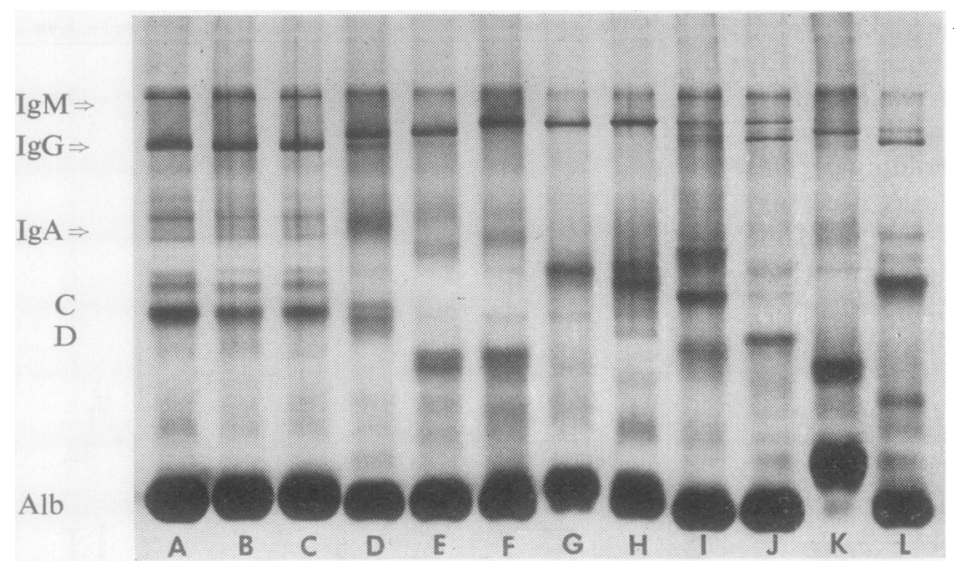

Fig. 2 Relative mobility of protein fractions in sera of different animal species during electrophoresis in multiple gradient gel: serum of (A) man, (B) man, (C) man, (D) ox, (E) sheep, (F) goat, (G) pig, (H) horse, (I) dog, (J) rabbit, (K) guinea-pig, (L) mouse.

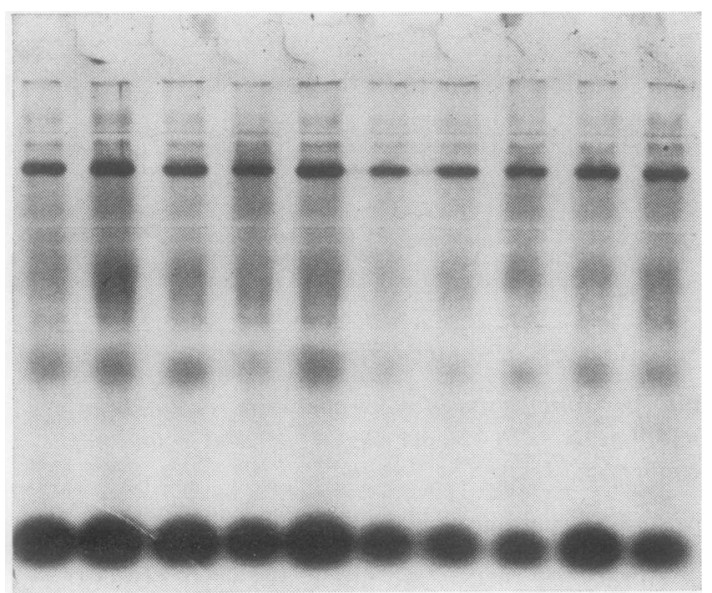

Fig. 3 Reproducibility of electrophoretic patterns of 10 consecutive bovine sera.

indicate that method 1 produces the best resolution. The slopes for other serum fractions showed similarly improved sharpness when method 1 was employed.

\begin{tabular}{|c|c|c|c|c|c|c|c|c|}
\hline \multirow[t]{3}{*}{ Method } & \multicolumn{8}{|c|}{ Transferrin Species } \\
\hline & \multicolumn{2}{|c|}{ Human } & \multicolumn{2}{|c|}{ Bovine } & \multicolumn{2}{|c|}{ Ovine } & \multicolumn{2}{|c|}{ Equine } \\
\hline & $L$ & $T$ & $L$ & $T$ & $L$ & $T$ & $L$ & $T$ \\
\hline $\begin{array}{l}1 \\
2 \\
3 \\
4\end{array}$ & $\begin{array}{r}18.69 \\
4.80 \\
4.42 \\
14.08\end{array}$ & $\begin{array}{r}24.68 \\
5.95 \\
3.00 \\
17.60\end{array}$ & $\begin{array}{l}9.60 \\
3.05 \\
2.82 \\
4.00\end{array}$ & $\begin{array}{r}16 \cdot 32 \\
5 \cdot 33 \\
7 \\
7 \cdot 55\end{array}$ & $\begin{array}{c}10.8 \\
3.20 \\
5.72\end{array}$ & $\begin{array}{l}- \\
-\end{array}$ & $\begin{array}{l}7 \cdot 73 \\
\overline{4.00} \\
2.83\end{array}$ & $\begin{array}{l}\text { 二 } \\
\text { - }\end{array}$ \\
\hline
\end{tabular}

Table II Mean slope of leading and trailing edges ( $\tan \theta)$ of transferrin peaks after electrophoresis by different methods

$L=$ slope of leading edge

$\mathbf{T}=$ slope of trailing edge

\section{Discussion}

Because initially the capping and well-forming gels contain only the leading and the common counter ion, the semi-solid layer acts only to slow the largest molecules during the very early part of the process, before the ionic boundary passes through. Further zone sharpening results from a difference in conductivity between the sample and the supporting gel (Hjertén, Jerstedt, and Tiselius, 1965) and, in the manner first described in starch-gel electrophoresis (Poulik, 1957), the resolution is increased again as the anionic boundary progresses through zones separated in the early phase of the migration.

Eventually, all the immunoglobulin fractions migrate into the $4 \frac{1}{2} \%$ layer. Strips cut from unfixed slabs, from some of which the semi-solid layer had been removed, were embedded in $1 \%$ agar; precipitin arcs, which developed when protein fractions diffused from the acrylamide towards troughs containing antiserum against human IgG, IgA, and $\operatorname{IgM}$ revealed that even the latter fraction had entered the $4 \frac{1}{2} \%$ gel (cf Felgenhauer, 1970). Hence, if vestigial immunoglobulin bands remain in the semi-solid layer, they are not detectable by present staining or immunodiffusion methods. The extent to which the IgM fraction migrated into the gel slab may be caused, at least in part, by the high peak voltage built up at the start of each pulse by the pulsed constant power unit.

Table II indicates that the system elicits protein segregation which is at least as good as, or better than, that of Margolis and Kenrick (1967); the casting of a discontinuous gel slab also possesses the merit of simplicity. The system has been used for both one- and two-dimensional electrophoresis.

Factors such as uncertainty of the precise length of path, absorption effects for different proteins, 
electroosmosis, minor differences in porosity caused by temperature variations, etc, may interact and render difficult the accurate measurement of the absolute mobility rates of proteins in porous gels. For this reason it may be considered advisable, for comparison between samples in successive runs, to relate the observed mobilities to those of a standard control serum; pooled normal human serum is employed in our current investigations which will be described in detail later.

The author wishes to thank Mr Gilles Goyette for his valuable technical assistance.

\section{References}

Allen, R. C., and Moore, D. J. (1966). A vertical flat-bed discontinuous electrophoresis system in polyacrylamide gel. Analyt. Biochem., 16, 457-465.

Allen, R. C., Moore, D. J., and Dilworth, R. H. (1969). A new rapid electrophoresis procedure employing pulsed power in gradient ge's at a continuous pH. (Abstr.) J. Histochem. Cytochem., 17, $189-190$.

Davis, B. J. (1964). Disc electrophoresis II. Method and application to human serum proteins. Ann. N.Y. Acad. Sci., 121, 404-427.

Dewar, J. H., and Latner, A. L. (1970). Immunological technique for identifying protein areas in gel slabs. Clin. chim. Acta, 28, 149-152.

Felgenhauer, K. (1970). Quantitation and specific detection methods after disc electrophoresis of serum proteins. Clin. Chim. Acta, 27, 305-312

Hjertén, S., Jers:edt, S., and Tiselius, A. (1965). Some aspects of the use of 'continuous' and 'discontinuous' buffer systems in polyacrylamide gel electrophoresis. Analyt. Biochem., 11, 219-223.

Margolis, J., and Kenrick, K. G. (1967). Polyacrylamide gel-electrophoresis across a molecular seive gradient. Nature (Lond.), 214, 1334-1336.

Ornstein, L. (1964). Disc electrophoresis I. Background and theory. Ann. N.Y. Acad. Sci., 121, 321-349.

Poulik, M. D. (1957). Starch gel electrophoresis in a discontinuous system of buffers. Nature (Lond.), 180, 1477-1479.

Raymond, S. (1962). A convenient apparatus for vertical gel electrophoresis. Clin. Chem., 8, 455-470.

Raymond, S., and Weintraub, L. (1959). Acrylamide gel as a supporting medium for zone electrophoresis. Science, 130, 711.

Slater, G. G. (1968). Pore-limit electrophoresis on a gradient of polyacrylamide gel. Analyt. Biochem., 24, 215-217. 